Original Research

\title{
How Carbon Trading Reduces China's Pilot Emissions: An Exploration Combining LMDI Decomposition and Synthetic Control Methods
}

\author{
Xiaoyuan Qi*, Ying Han \\ School of Business Administration, Northeastern University, Shenyang, China
}

Received: 22 October 2019

Accepted: 10 December 2019

\begin{abstract}
Carbon trading is an effective market emission reduction mechanism. In order to formulate effective market policy, it is necessary to access a deep understanding of carbon trading policy implementation. So based on the panel data of 30 regions in China from 2001 to 2016, we investigated the factors of carbon emissions through LMDI decomposition approach, and then discuss the effect of policy implementation in eight pilots using synthetic control methods. The main conclusions are as follows: The distribution tendency of carbon emissions in China is obviously high in the east and low in the west, and the proportion of these regions' emissions to the total are respectively around $48.7 \%, 34.0 \%$ and $17.3 \%$. The total carbon emissions effect can be divided into five parts, which respectively are energy structure, energy intensity, economic development, urbanization and population size. The gap between real and synthetic carbon emissions in each pilot is enlarged after implementation. The probability of the real policy effect is $4.35 \%$, which at a $5 \%$ significant level refuses the original assumption that there is no policy effect, and shows that the carbon trading policy can effectively reduce emissions and achieve the goal of total control.
\end{abstract}

Keywords: carbon emissions, carbon trading, implementation effect, LMDI decomposition, synthetic control methods

\section{Introduction}

Compared with the means of administrative order control, the mechanism of market-oriented emission reduction has the advantages of saving transaction

*e-mail: xiaoyuanqi_neu@163.com costs, weakening political resistance, promoting technical innovation and mobilizing the enthusiasm of economic subjects [1-4]. The focus of the debate on market-oriented emission reduction mechanisms is on which is more effective between price control and quantity control $[5,6]$. In theory, they are equivalent under deterministic conditions [7]. But in practice, uncertainty and market defects make them significantly different $[8,9]$. As an effective quantitative control tool, 
emission trading has its long-term advantages gradually highlighted in environmental governance [10, 11]. The essence of emission trading is to take pollution as a negative external problem, and then achieve emission abatement through the internalization of external costs. Recently, carbon trading is one of the mainstream flexible mechanisms in global climate governance, and it can achieve effective emission reduction at a lower cost.

As the largest carbon emitter in the world, China has carried out pilot carbon trading in Beijing, Shanghai, Guangdong, Shenzhen, Tianjin, Hubei, Chongqing and Fujian, while launching the national unified carbon market at the end of 2017. China's carbon market is expected to become the world's largest carbon market, surpassing the EU ETS. China clearly presents the goal that "carbon intensity will be reduced by $40-45 \%$ by 2020 and $60-65 \%$ by 2030 ". China has already achieved the 2020 goal, and it is of great significance to achieve the 2030 goal in order to build a perfect and unified carbon market. Therefore, it is necessary to investigate the policy implementation of carbon trading in the operation of the pilots, which is of great significance to formulate a perfect national unified carbon market mechanism.

In fact, the most direct measurement of carbon reduction is carbon emissions, and the factors of carbon emissions can become the actual transmission path of emissions. As for the factors of carbon emissions, different scholars refer to different factors, such as energy consumption, energy structure and economic development [12]. The methods adopted by scholars mainly focus on the structural decomposition method [13-17], the exponential decomposition method [18-20] and the self-set measurement model. In this paper, the LMDI exponential decomposition method is mainly used to decompose the main driving factors of carbon emissions due to the advantages of LMDI, which can not only completely decompose the object, but also cannot be disturbed by the remaining problems. Moreover, it can handle the problem of zero and negative values in the data while being applicable to the analysis of most cases.

Literature mainly discusses the effect of carbon trading policy implementation from a macro perspective. The application of methods to evaluate the implementation of carbon trading mainly includes the situation analysis method, CGE model, DEA method, difference-in-difference (DID) method and a combination method of PSM and DID. More and more scholars have evaluated the policy effect of carbon trading based on the computable general equilibrium method, and believe that the application and promotion of the carbon-trading market can effectively reduce regional carbon emissions, promote regional economic development and reduce costs of carbon abatement [21-25]. In recent years, with the development of experimental economics, research on the effect of policy implementation by using quasi-natural experiments has emerged and has been used in carbon trading policy [2629]. The DID method needs to meet the four hypotheses, including the common trend hypothesis, the common interval hypothesis, the exogenous hypothesis and the non-interactive effect hypothesis. Only in this case can this method effectively identify the policy intervention effect. The common trend hypothesis is the key of DID. It is a semi-parameter identification strategy because of its functional dependence, so it is subjective. This paper studies the effect of carbon market policy by using the synthetic control method (SCM) from the macro perspective. SCM, as an effective and objective policy evaluation tool, can carry out the anti-fact structure to the experimental group by giving the optimal weight of the control group. After the policy intervention, the difference between the experimental group and the control group is the effect of the policy intervention. This approach can make up for the deficiency of DID. And there is no literature currently to evaluate the implementation of carbon trading in China using the method combining LMDI and SCM, which not only investigates the implementation of carbon trading objectively, but also completely decomposes the carbon emissions.

Therefore, this paper actually proposes a more systematic research framework as follows. Based on the panel data of energy consumption in 30 regions of China, this paper first measures carbon emissions in each region, and then decomposes driving factors of carbon emissions using the LMDI method. Finally, the inverse facts are simulated by SCM using the decomposed driving factors, and the counter-fact of the pilot carbon market experimental group is synthesized by using the weight of the control group. So it can judge the implementation effect of carbon market policy and provide empirical support for the formulation of more effective carbon market policy in the future.

\section{Methodology and Data}

\section{Variable Selection and Data Source}

Energy consumption: The main source of carbon emissions is fossil energy consumption, so it uses energy consumption in regions. Data is from the China Energy Statistics Yearbook.

Carbon emissions: Carbon emissions are calculated by the following step. First deduct industrial use as raw materials, and thermal power processing conversion and thermal energy processing conversion from various energy consumption, and then multiplied by carbon emission coefficients. Data is from the China Energy Statistics Yearbook and the IPCC National Greenhouse Gas Inventory Guide.

Energy structure: Given that coal is still the main fossil fuel for energy consumption, a proportion of coal consumption is used to indicate the energy structure. 
Table 1. Descriptive statistics for variables.

\begin{tabular}{|c|c|c|c|c|c|}
\hline Vairable & Obs & Mean & Std.Dev. & Min & Max \\
\hline Energy intensity & 480 & 0.0001135 & 0.0002302 & 0 & 0.0020338 \\
\hline Economic development & 480 & 17255.95 & 9554.967 & 5267.42 & 57691.7 \\
\hline Urbanization & 480 & 0.8667246 & 0.2635148 & 0.1052559 & 1.732696 \\
\hline Population size & 480 & 433.052 & 2612.268 & 523.1 & 10999 \\
\hline Energy structure & 480 & 0.3256745 & 0.1444853 & 0 & 0.9441753 \\
\hline $\mathrm{CO}_{2}$ & 480 & 24968.7 & 68764.83 & 0 & 1434350 \\
\hline
\end{tabular}

The higher the proportion of coal consumption, the greater the carbon emissions, the more unfavorable to control emissions. And the data are derived from the China Energy Statistics Yearbook.

Energy intensity: the ratio of energy consumption to economic development of the region. Energy intensity, as a common index of energy comprehensive utilization efficiency, not only reflects the economic and technical efficiency of energy utilization, but also can be used to compare the dependence of economic development on energy in different regions. Reducing energy intensity in the production process is the core goal of effectively controlling carbon emissions [30]. It uses the proportion of energy consumption to the disposable income of the population to indicate energy intensity. Data is derived from the China Energy Statistics Yearbook and the China Household Survey Yearbook.

Economic development: The relationship between economic development and carbon emissions has long been the focus of scholars' attention, which is mainly discussed regarding the existence, shape and inflection point of the environmental Kuznets curve [31-33]. So economic development is an important driving factor of carbon emissions. This paper uses per capita disposable income to indicate the level of economic development, and the data comes from the China Household Survey Yearbook.

Urbanization rate: a common index of urbanization level. China's urbanization mode has changed from the previous rapid but inefficient mode to the highquality mode whose services and free markets play a greater role [34]. The promotion of urbanization is very important to effectively control emissions. This paper uses the proportion of urban population to the total population at the end of the year to indicate urbanization, and the data comes from the China Urban Statistical Yearbook.

Population size: Carbon emissions from human activities that exceed environmental carrying capacity are the direct causes of global warming and climate change. So population size is an important factor of carbon emissions. The total population of the region is used as a measure of population size, and the data comes from the China Statistical Yearbook.

More details about the descriptive statistics for variables can be seen in Table 1 .
Model

\section{A Model for Calculating Carbon Emissions}

In this paper, The 2006IPCC Guidelines for National Greenhouse Gas inventories prepared by the United Nations Intergovernmental Panel on Climate Change (IPCC) are used to estimate carbon emissions according to the amount of fuel burned and the default emission factors. Due to the incomplete data in Tibet, it selects the relevant energy consumption data of 30 regions in China from 2001 to 2016 to estimate carbon emissions. Carbon emissions are the product of all kinds of energy consumption and energy carbon emission coefficient. The specific estimation methods are as follows:

$$
\begin{gathered}
C O_{2}=\sum_{i=1}^{i} C_{2 i}=\sum_{i=1}^{i} E C_{i} \cdot N C V_{i} \cdot C E F_{i} \\
C E F_{i}=C C_{i} \cdot C O F_{i} \cdot(44 / 12)
\end{gathered}
$$

...where $\mathrm{CO}_{2}$ is the total amount of carbon emissions. $i$ is a variety of energy fuels, $i=1, \ldots, 8$, and they represent eight kinds of energy fuels, respectively: coal, coke, crude oil, gasoline, kerosene, diesel oil, fuel oil and natural gas. $E C_{i}$ represents a variety of energy consumption. In order to avoid double calculation, it uses the energy balance table of 30 regions from 2001 to 2016 to eliminate the input, loss in the process of energy and conversion as well as the part of industrial production used as raw materials and materials in each region year by year. Finally, the net energy consumption of each region is obtained. $N C V_{i}$ is average low calorific value of various sources of energy. $C E F_{i}$ is carbon emission coefficients of various sources of energy. $C C_{i}$ is the carbon content of the unit heat value of various energy. $\mathrm{COF}_{i}$ is carbon oxidation factor or carbon oxidation rate of various energy. (44/12) is the molecular weight ratio of carbon dioxide to carbon. The specific reference values are shown in Table 2.

\section{Decomposition Model of Influencing Factors of Carbon Emission}

According to Brännlund et al. [35], the basic decomposition model is as follows: 
Table 2. Coefficient of carbon emissions from various of energies.

\begin{tabular}{|c|c|c|c|c|c|c|c|c|}
\hline Energy categories & $\begin{array}{l}\text { Raw } \\
\text { coal }\end{array}$ & Coke & $\begin{array}{l}\text { Crude } \\
\text { oil }\end{array}$ & Gasoline & $\begin{array}{c}\text { Fuel } \\
\text { oil }\end{array}$ & $\begin{array}{l}\text { Natural } \\
\text { gas }\end{array}$ & $\begin{array}{l}\text { Diesel } \\
\text { oil }\end{array}$ & Kerosene \\
\hline Average low fever $(\mathrm{KJ} / \mathrm{kg})$ & 20908 & 28435 & 41816 & 43070 & 41816 & 38931 & 42652 & 43070 \\
\hline Standard coal measures (kgce/kg) & 0.7143 & 0.9714 & 1.4286 & 1.4714 & 1.4286 & 1.33 & 1.4571 & 1.4714 \\
\hline $\begin{array}{l}\text { Carbon content per unit calorific value } \\
\text { (ton carbon / TJ) }\end{array}$ & 26.37 & 29.5 & 20.1 & 18.9 & 21.1 & 15.3 & 20.2 & 19.5 \\
\hline Carbon oxidation rate & 0.94 & 0.93 & 0.98 & 0.98 & 0.98 & 0.99 & 0.98 & 0.98 \\
\hline Carbon dioxide emission coefficient $\left(\mathrm{kg}-\mathrm{CO}_{2} / \mathrm{kg}\right)$ & 1.9003 & 2.8604 & 3.0202 & 2.9251 & 3.1705 & 2.1622 & 3.0959 & 3.0179 \\
\hline
\end{tabular}

Source: data from China Energy Statistics Yearbook, IPCC National greenhouse Gas inventory guidelines

$$
D C_{i}=\sum_{j} \frac{D C_{i j}}{D E_{i j}} \cdot \frac{D E_{i j}}{D E_{i}} \cdot \frac{D E_{i}}{L_{i}} \cdot \frac{L_{i}}{R_{i}} \cdot \frac{R_{i}}{P_{i}} \cdot P_{i}
$$

...where $i=1,2, \ldots, 30$, respectively indicating the regions in the sample. $j=1, \ldots, 8$ respectively represent eight kinds of energy sources, including coal, coke, crude oil, gasoline, kerosene, diesel oil, fuel oil, and natural gas. $D C_{i j}$ represents carbon emissions from the consumption of category $j$ energy in area i. $D E_{i j}$ represents the amount of $j$ energy consumption in area $i$; $D E_{i}$ represents regional energy consumption; $L_{i}$ represents regional disposable income; $R_{i}$ represents the number of urban population at the end of the year; $P_{i}$ represents the total population of the region at the end of the year.

Order:

$$
F_{j}=\frac{D C_{i j}}{D E_{i j}} ; S_{i j}=\frac{D E_{i j}}{D E_{i}} ; P E_{i}=\frac{D E_{i}}{L_{i}} ; M_{i}=\frac{L_{i}}{R_{i}} ; H_{i}=\frac{R_{i}}{P_{i}}
$$

The underlying model can be represented as:

$$
D C_{i}=\sum_{j} F_{j} \cdot S_{i j} \cdot P E_{i} \cdot M_{i} \cdot H_{i} \cdot P_{i}
$$

In the formula, $F_{j}$ represents the carbon emission coefficient of energy, and it is usually taken as a constant. So in the process of decomposition, the contribution value of $F$ is always 0 , and the contribution rate is always 1 , which cannot be used as a factor for evaluation. $S_{i j}$ indicates the proportion of type $j$ energy consumption in area $i$ to its total energy consumption, that is, energy structure. $P E_{i}$ represents the amount of energy spent on the purchase of disposable income by the residents of region $i$, that is, energy intensity. $M_{i}$ represents regional per capita disposable income, that is, economic development. $H_{i}$ indicates the proportion of urban population to the total population at the end of the year, that is, urbanization rate. $P_{i}$ expresses the total population at the end of the region $i$, that is, population size. Other symbols have the same meaning as formula (3).

According to the need of this paper, the form of additive decomposition is adopted in the LMDI decomposition method. And the model can be expressed as follows:

$$
\begin{array}{r}
\Delta D C_{i}=\Delta D C_{S_{i j}}+\Delta D C_{P E_{i}}+\Delta D C_{M_{i}}+\Delta D C_{H_{i}}+\Delta D C_{P_{i}} \\
=\frac{\Delta D C_{i}}{\Delta\left(\ln D C_{i}\right)} \cdot\left(\ln \frac{S_{i j, t}}{S_{i j, 0}}+\ln \frac{P E_{i, t}}{P E_{i, 0}}+\ln \frac{M_{i, t}}{M_{i, 0}}+\ln \frac{H_{i, t}}{H_{i, 0}}+\ln \frac{P_{i, t}}{P_{i, 0}}\right)
\end{array}
$$

\section{Evaluation Model of Carbon Trading Policy Implementation Effect}

In this paper, a new policy evaluation method - synthetic control - is proposed by Abadie and Gardeazabal [36] and Abadie et al. [37], which is applied in evaluating the effectiveness of the pilot carbon market in China.

The basic idea of the synthetic control method is as follows. Although any individual in the control group is not similar to the intervention group, a synthetic control group is constructed by giving an individual weight to each control group and a synthetic control group is constructed after weighted average. The behavior of the synthetic control group is very similar to that before the policy intervention in the intervention group, so it is expected that if there is no policy intervention in the treatment group, the behavior of the intervention group will still be very similar to that of the synthetic control group. That is to say, the ex post factor results of the synthetic control group can be used as the counter factual results of the individuals in the intervention group, and the difference between the treatment group and the synthetic control group is the influence of policy intervention.

Unlike the DID approach, there is only one individual in the treatment group in SCM, usually a city, region or country. The causal effect for an individual is shown in formula (6).

$$
\text { eff } f_{i t}=Y_{1 i t}-Y_{0 i t}, \quad i=1, \ldots, N+1, \quad t=1, \ldots, T
$$

Assume that area 1 is subject to policy intervention after phase $\mathrm{T}_{0} . i$ means the number of areas. $t$ indicates time. eff ${ }_{i t}$ represents the policy effect of region $i$ in period $t$, that is, the individual causality effect. $Y_{l i t}$ indicates the potential outcome of the individual $i$ 's acceptance of policy intervention at the $t$ period. $Y_{0 i t}$ 
represents the potential outcome of an individual who is not subject to policy intervention during period $t$. In addition, the intervention state of individual $i$ in period $t$ is represented by $\mathrm{D}_{\mathrm{it}}$, where $\mathrm{D}_{\mathrm{it}}=1$ is subject to policy intervention during period $t$ for an individual $i$, otherwise takes 0 . And it is shown in formula (7).

$$
D_{i t}= \begin{cases}1 & i=1, t>T_{0} \\ 0, & \text { other }\end{cases}
$$

Then the observation results of individual $i$ in period $t$ can be expressed in formula (8).

$$
Y_{i t}=D_{i t} Y_{i t}+\left(1-D_{i t}\right) Y_{0 i t}=Y_{0 i t}+e f f_{i t} D_{i t}
$$

The evaluated effect of the target policy is as follows.

$$
e f f_{i t}=Y_{11 t}-Y_{01 t}=Y_{1 t}-Y_{01 t}
$$

...where $Y_{01 t}$ can be represented by the following factor model, as shown in formula (9):

$Y_{0 i t}=\delta_{t}+\theta_{t} Z_{i}+\lambda_{t} \mu_{i}+\varepsilon_{i t}, \quad i=1, \ldots, N+1, \quad T=1, \ldots, T$

...where the first term $\delta_{t}$ represents the time fixed effect, and $\theta Z_{i}$ represents the observable vector, which is not affected by policy intervention and does not change with time. $\lambda \mu_{i}$ denotes the unobservable "interactive fixed effect", that is, the product of individual fixed effect and time fixed effect [38]. $\varepsilon_{i}$ denotes random disturbance term, and other variables have the same meaning as above.

The selection of weight $\mathrm{W}$ is the key to SCM. Then consider the $\mathrm{N}^{*} 1$ dimension weight vector $\mathrm{W}=\left(w_{2}, \ldots, w_{N+1}\right)$, which needs to satisfy $w \mathrm{j} \geq 0, \mathrm{j}=2, \ldots, \mathrm{N}+1$, and $w_{2}, \ldots, w_{N+1}=1$. Each specific weight matrix vector $\mathrm{W}$ represents a specific synthesis control, and for the $\mathrm{W}$, SCM shown in formula (10):

$$
\sum_{j=2}^{N+1} w_{j} Y_{j t}=\delta_{t}+\theta \sum_{j=2}^{N+1} w_{j} Z_{j}+\lambda \sum_{j=2}^{N+1} w_{j} \mu_{j}+\sum_{j=2}^{N+1} \varepsilon_{j t}
$$

Suppose there exists a weight $\mathrm{W}=\left(w_{2}{ }_{2}, \ldots, w_{N+1}{ }^{*}\right)^{\prime}$, so that formula (11) is shown as follows:

$\sum_{j=2}^{N+1} w_{j}^{*} Y_{j 1}=Y_{11}, \sum_{j=2}^{N+1} w_{j}^{*} Y_{j 2}=Y_{12}, \ldots, \sum_{j=2}^{N+1} w_{j}^{*} Y_{j T_{0}}=Y_{1 T_{0}}, \sum_{j=2}^{N+1} w_{j}^{*} Z_{j}=Z_{1}$

If $\sum_{t=1}^{T_{0}} \lambda_{t}^{\prime} \lambda_{n}$ is not strange, there exists a relationship in formula (12):

$$
Y_{01 t}-\sum_{j=2}^{N+1} w_{j}^{*} Y_{j t}=\sum_{j=2}^{N+1} w_{j}^{*} \sum_{s=1}^{T_{0}} \lambda_{t}\left(\sum_{n=1}^{T_{0}} \lambda_{n}^{\prime} \lambda_{n}\right)^{-1} \lambda_{s}^{\prime}\left(\varepsilon_{j s}-\varepsilon_{1 s}\right)
$$

Synthetic control weight $\mathrm{W}=\left(w^{*}, \ldots, w^{*}{ }_{N+1}\right)^{\prime}$ minimizes the following distance:

$$
\begin{gathered}
\left\|X_{1}-X_{0} W\right\|=\sqrt{X_{1}-X_{0} W^{\prime} V\left(X_{1}-X_{0} W\right)} \\
=\sqrt{\sum_{m=1}^{M} v_{m}\left(X_{1 m}-X_{0 m} W\right)^{2}}
\end{gathered}
$$

...where $v$ is a symmetric positive definite matrix of $\mathrm{M}^{*} \mathrm{M}$, which is usually a diagonal matrix. Diagonal element $v_{m}, m=1, \ldots, \mathrm{M}$, is a weight, which reflects the relative importance in the difference of covariables between the intervention group and the control group. $X_{j m}$ is the $m$ covariate of individual $j$. The selection of $v_{l}, \ldots, v_{m}$ reflects the prediction capability of the covariates, and the matrix $V$ that minimizes the prior mean square prediction error (MSPE) can be selected, that is, select $V$ to minimize equation (14), thereby determining the weight matrix $\mathrm{W}^{*}$.

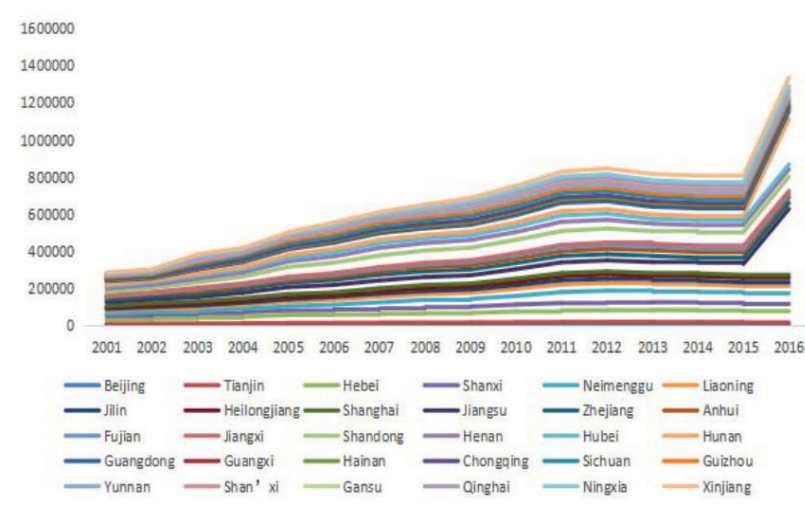

Fig. 1. Estimation of carbon emissions in sub-regions from 2001 to 2016 .

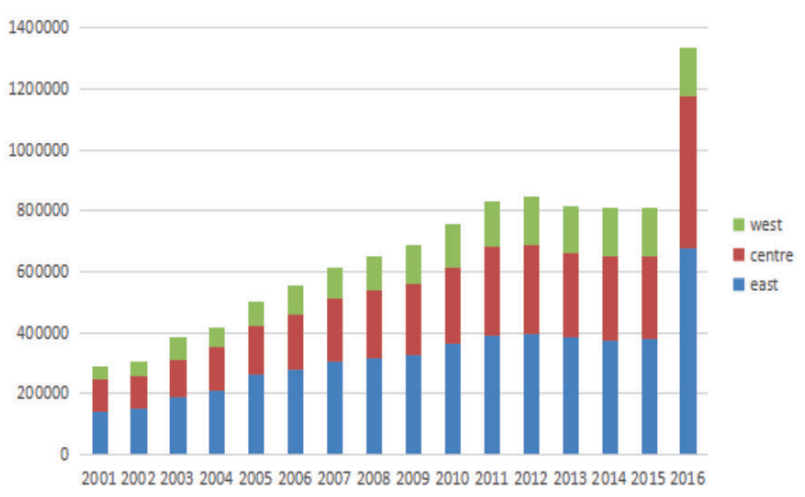

Fig. 2. Carbon emissions from the sub-regions of eastern, central and western China. 


$$
\sum_{t=1}^{T_{0}}\left(Y_{1 t}-\sum_{j=2}^{N+1} w_{j}^{*}(V) Y_{j t}\right)^{2}
$$

\section{Results and Discussion}

\section{Results and Analysis of Carbon Emission Measurement}

The results of carbon emissions are shown in Fig. 1. The comparative results of carbon emissions in the eastern, central and western parts of China are shown in Fig. 2.

As seen in Fig. 1, carbon emissions show a gradual increasing trend, and after 2011 the carbon emissions have a significant downward trend, which may be caused by the effective implementation of the government's policies on emission reduction control. With the development of the economy, energy consumption is still dominated by fossil fuel, and carbon emissions still show an overall upward trend. In Fig. 2, the overall trend of carbon emissions from the perspective of east to west shows that the eastern carbon emissions are

Table 3. Comparison of the trend of carbon emissions and their influencing factors in each region

\begin{tabular}{|c|c|c|c|c|c|c|}
\hline Regions & Carbon emission & Energy intensity & $\begin{array}{c}\text { Economic } \\
\text { development }\end{array}$ & Urbanization & People scale & Energy structure \\
\hline Beijing & Rise and then fall & fall & rise & Fall and then rise & Rise and then fall & fall \\
\hline Tianjin & Rise and then fall & fall & rise & Fall and then rise & rise & Fall and then rise \\
\hline Hebei & Rise and then fall & Rise and then fall & rise & rise & rise & fall \\
\hline Shanxi & Rise and then fall & fall & rise & Rise and then fall & rise & Rise and then fall \\
\hline Neimenggu & Rise and then fall & rise & rise & Rise and then fall & rise & Fall and then rise \\
\hline Liaoning & Rise and then fall & Rise and then fall & rise & rise & Rise and then fall & Fall and then rise \\
\hline Jilin & Rise and then fall & fall & rise & Rise and then fall & rise & Fall and then rise \\
\hline Heilongjiang & rise & Rise and then fall & rise & rise & Rise and then fall & rise \\
\hline Shanghai & Rise and then fall & Rise and then fall & Fall and then rise & fall & rise & Rise and then fall \\
\hline Jianhsu & Rise and then fall & Rise and then fall & rise & Fall and then rise & Fall and then rise & fall \\
\hline Zhejiang & Rise and then fall & Rise and then fall & rise & fall & rise & Rise and then fall \\
\hline Anhui & rise & fall & rise & Rise and then fall & Fall and then rise & Rise and then fall \\
\hline Fujan & Rise and then fall & fall & rise & rise & rise & Rise and then fall \\
\hline Jiangxi & rise & fall & rise & rise & rise & Rise and then fall \\
\hline Shandong & rise & Rise and then fall & rise & Fall and then rise & rise & fall \\
\hline Henan & Rise and then fall & Rise and then fall & rise & rise & fall & fall \\
\hline Hubei & Rise and then fall & fall & fall & rise & rise & Rise and then fall \\
\hline Hunan & rise & Rise and then fall & rise & Rise and then fall & Fall and then rise & Rise and then fall \\
\hline Guangdong & Rise and then fall & Rise and then fall & rise & fall & rise & rise \\
\hline Guangxi & Rise and then fall & Rise and then fall & rise & rise & Fall and then rise & Rise and then fall \\
\hline Hainan & Rise and then fall & fall & rise & rise & rise & Fall and then rise \\
\hline Chongqing & Rise and then fall & Rise and then fall & rise & Rise and then fall & rise & fall \\
\hline Sichuan & Rise and then fall & fall & rise & rise & fall & fall \\
\hline Guizhou & Rise and then fall & Rise and then fall & rise & rise & fall & Rise and then fall \\
\hline Yunnan & Rise and then fall & fall & rise & rise & rise & Rise and then fall \\
\hline Shan'xi & rise & Rise and then fall & rise & rise & rise & Rise and then fall \\
\hline Gansu & Rise and then fall & Rise and then fall & Fall and then rise & rise & Fall and then rise & fall \\
\hline Qinghai & rise & Rise and then fall & rise & rise & rise & fall \\
\hline Ningxia & rise & fall & rise & Rise and then fall & rise & rise \\
\hline Xinjiang & rise & fall & rise & rise & rise & Fall and then rise \\
\hline
\end{tabular}


higher than the central, and the western is the lowest. Their proportion of carbon emissions in the regions to the total are respectively around $48.7 \%, 34.0 \%$ and $17.3 \%$. The reason for increasing carbon emissions in central and western China year by year lies in the fact that the policies for promoting the development of the western regions and the rise of the central regions stimulate regional economic growth, which brings about an increase of carbon emissions at the same time. From the perspective of industrial transfer, the eastern regions first develop, and the policy in the eastern regions may lead to some high-emission industries transfer to the central and western regions, which may promote the economic development of the central and western regions. And then the central and western regions may become the "pollution of heaven". In order to avoid them becoming the "pollution paradise" and promote the high quality development of China, it is urgent to analyze the key factors of carbon emissions.

\section{Decomposition Results and Analysis of Carbon Emission Factors in Different Regions}

According to the above setting of LMDI decomposition model, taking 2003 as the base period, the total effect of carbon emissions can be decomposed into energy intensity, economic development, urbanization, population size and energy structure. The comparative results of carbon emissions and their influencing factors in each region are shown in Table 3, according to which, compared with the base period, most of the total effects of carbon emissions in each region are increasing year by year, and the contribution of energy intensity effect and economic development effect to regional carbon emissions is relatively obvious, followed by energy structure effect, population size effect and urbanization effect. The increasing state of the total effect reflects that the effect of current carbon emission control is still much higher than that in the base period. It also indicates that the local government has taken better measures to reduce carbon emissions, which have been effectively controlled.

Evaluation Results and Analysis of Carbon Market Policy Implementation

SCM proposed by Abadie et al. (2003 and 2010) are used to estimate the policy effect. The pilots are eliminated in the same period, and other regions without

Table 4. Weight determination of each synthetic pilot region.

\begin{tabular}{|c|c|c|c|c|c|c|c|}
\hline Weight & $\begin{array}{c}\text { Synthetic } \\
\text { Beijing }\end{array}$ & $\begin{array}{l}\text { Synthetic } \\
\text { Shanghai }\end{array}$ & $\begin{array}{c}\text { Synthetic } \\
\text { Guangdong }\end{array}$ & $\begin{array}{l}\text { Synthetic } \\
\text { Tianjin }\end{array}$ & $\begin{array}{l}\text { Synthetic } \\
\text { Hubei }\end{array}$ & $\begin{array}{l}\text { Synthetic } \\
\text { Chongqing }\end{array}$ & $\begin{array}{c}\text { Synthetic } \\
\text { Fujian }\end{array}$ \\
\hline Yunnan & 0 & 0 & 0 & 0 & 0 & 0.109 & 0 \\
\hline Neimenggu & 0 & 0 & 0 & 0 & 0 & 0 & 0 \\
\hline Jilin & 0 & 0 & 0 & 0 & 0 & 0 & 0.207 \\
\hline Sichuan & 0 & 0 & 0.418 & 0 & 0.119 & 0 & 0.31 \\
\hline Ningxia & 0 & 0 & 0 & 0 & 0 & 0 & 0.385 \\
\hline Anhui & 0 & 0 & 0 & 0 & 0.327 & 0.155 & 0 \\
\hline Shandong & 0 & 0 & 0.101 & 0 & 0 & 0 & 0 \\
\hline Shanxi & 0 & 0.251 & 0 & 0 & 0.086 & 0 & 0.071 \\
\hline Guangxi & 0 & 0 & 0 & 0 & 0 & 0 & 0 \\
\hline Xinjiang & 0 & 0 & 0 & 0 & 0 & 0 & 0 \\
\hline Jiangsu & 0 & 0 & 0.481 & 0 & 0 & 0 & 0 \\
\hline $\begin{array}{l}\text { Jiangxi } \\
\end{array}$ & 0 & 0 & 0 & 0 & 0 & 0 & 0.002 \\
\hline Hebei & 0 & 0 & 0 & 0 & 0.002 & 0 & 0 \\
\hline Henan & 0 & 0 & 0 & 0 & 0.098 & 0 & 0 \\
\hline Zhejiang & 0.202 & 0.217 & 0 & 0.125 & 0 & 0.076 & 0 \\
\hline Hainan & 0 & 0 & 0 & 0 & 0.064 & 0 & 0.022 \\
\hline Hunan & 0 & 0 & 0 & 0 & 0 & 0 & 0 \\
\hline Gansu & 0.039 & 0 & 0 & 0.473 & 0 & 0 & 0 \\
\hline Guizhou & 0 & 0 & 0 & 0 & 0 & 0 & 0 \\
\hline Liaoning & 0 & 0 & 0 & 0 & 0.304 & 0 & 0 \\
\hline Shan'xi & 0 & 0 & 0 & 0 & 0 & 0.085 & 0.003 \\
\hline Qinghai & 0.759 & 0.532 & 0 & 0.297 & 0 & 0.575 & 0 \\
\hline Heilongjiang & 0 & 0 & 0 & 0.105 & 0 & 0 & 0 \\
\hline
\end{tabular}




\begin{tabular}{|c|c|c|c|c|c|c|c|c|c|c|c|c|c|c|}
\hline 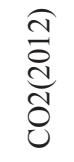 & 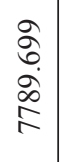 & 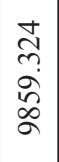 & $\begin{array}{l}\infty \\
\stackrel{-}{0} \\
\stackrel{0}{=} \\
=\end{array}$ & 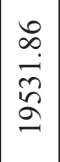 & 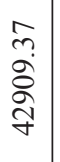 & 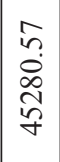 & $\begin{array}{l}\partial \\
\hat{े} \\
o \\
o \\
0\end{array}$ & $\begin{array}{l}\tilde{b} \\
\dot{+} \\
\dot{0} \\
\dot{q}\end{array}$ & 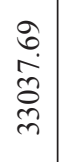 & 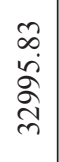 & $\begin{array}{l}\vec{b} \\
\dot{\vec{n}} \\
\stackrel{n}{=}\end{array}$ & 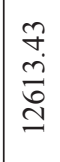 & 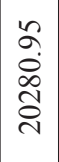 & \\
\hline 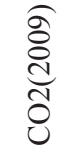 & 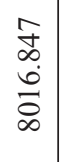 & $\mid \begin{array}{l}2 \\
\tilde{c} \\
\dot{0} \\
\infty \\
\infty\end{array}$ & $\begin{array}{l}\hat{n} \\
2 \\
\hat{0} \\
n \\
n\end{array}$ & $\begin{array}{l}\vec{m} \\
\vec{d} \\
\stackrel{0}{0} \\
-\end{array}$ & $\begin{array}{l}\infty \\
\stackrel{0}{a} \\
\vec{b} \\
\vec{n}\end{array}$ & $\begin{array}{l}\infty \\
\infty \\
0 \\
\infty \\
\tilde{n} \\
\tilde{m}\end{array}$ & 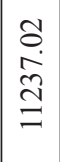 & 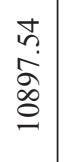 & $\begin{array}{l}\hat{0} \\
\dot{0} \\
\dot{0} \\
i \\
\end{array}$ & $\begin{array}{l}\infty \\
\stackrel{\infty}{J} \\
\stackrel{\vec{\sim}}{\vec{N}}\end{array}$ & $\underset{\stackrel{+}{\dot{J}}}{\stackrel{\Xi}{\Xi}}$ & $\begin{array}{l}\Omega \\
\infty \\
0 \\
0 \\
0 \\
0 \\
0\end{array}$ & 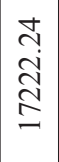 & \\
\hline 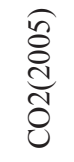 & 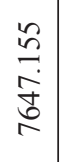 & $\begin{array}{l}\infty \\
\hat{\imath} \\
\hat{n} \\
\frac{b}{b}\end{array}$ & 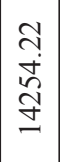 & 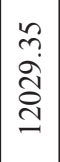 & $\begin{array}{l}\hat{m} \\
\text { ò } \\
\dot{d} \\
\dot{m}\end{array}$ & $\begin{array}{l}\hat{a} \\
\dot{a} \\
\dot{d} \\
\text { dे }\end{array}$ & 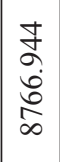 & 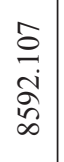 & 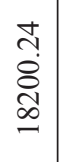 & 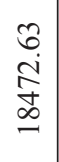 & $\mid \begin{array}{l}m \\
0 \\
\dot{a} \\
\dot{a} \\
0\end{array}$ & $\begin{array}{l}\overrightarrow{\hat{\alpha}} \\
\hat{\alpha} \\
\infty \\
0\end{array}$ & $\begin{array}{l}n \\
\stackrel{n}{n} \\
\stackrel{5}{=}\end{array}$ & \\
\hline 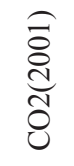 & 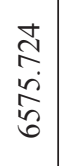 & 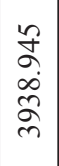 & $\mid \begin{array}{l}0 \\
0 \\
0 \\
0 \\
b \\
b \\
0\end{array}$ & 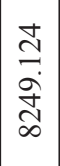 & 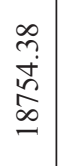 & 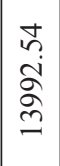 & 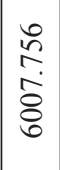 & $\mid \begin{array}{c}\hat{a} \\
\dot{b} \\
\dot{\vec{d}} \\
i \\
i\end{array}$ & $\begin{array}{c}0 \\
0 \\
\infty \\
0 \\
0 \\
-0 \\
0\end{array}$ & $\begin{array}{l}\tilde{\sigma} \\
\infty \\
0 \\
0 \\
0\end{array}$ & $\begin{array}{c}\infty \\
\infty \\
n \\
\tilde{n} \\
\tilde{n}\end{array}$ & 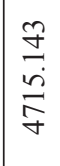 & 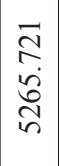 & \\
\hline 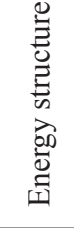 & 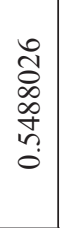 & 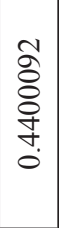 & 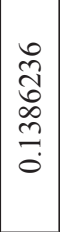 & 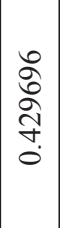 & 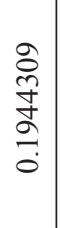 & 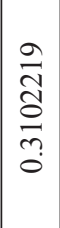 & 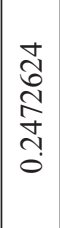 & 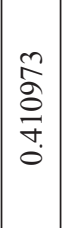 & 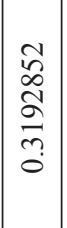 & $\begin{array}{l}\text { ठठ } \\
\sigma \\
\sigma \\
\sigma \\
\sigma\end{array}$ & $\mid \begin{array}{c}1 \\
0 \\
+ \\
0 \\
0 \\
e \\
0 \\
0 \\
0\end{array}$ & $\mid \begin{array}{c}\tilde{n} \\
\hat{n} \\
\tilde{\infty} \\
\tilde{o} \\
\tilde{0}\end{array}$ & 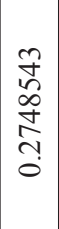 & \\
\hline $\begin{array}{l}\frac{0}{\pi} \\
0 \\
0 \\
0 \\
0 \\
0 \\
0 \\
0\end{array}$ & $\begin{array}{l}m \\
\tilde{D} \\
\stackrel{0}{0} \\
\infty \\
0\end{array}$ & $\begin{array}{l}0 \\
2 \\
\infty \\
0 \\
0 \\
0\end{array}$ & $\begin{array}{l}n \\
n \\
\tilde{2} \\
\tilde{\sigma} \\
\text {. }\end{array}$ & 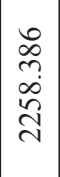 & $\begin{array}{l}\vec{\partial} \\
\infty \\
\vec{\omega} \\
\vec{\infty} \\
\infty\end{array}$ & 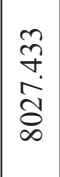 & $\begin{array}{l}\overrightarrow{\tilde{n}} \\
\infty \\
\dot{j} \\
\stackrel{+}{=}\end{array}$ & 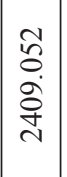 & $\begin{array}{l}\hat{\imath} \\
\hat{a} \\
\grave{D} \\
i n\end{array}$ & $\begin{array}{l}\text { ơ } \\
\text { d. } \\
\text { n. } \\
\text { in }\end{array}$ & 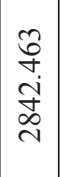 & $\begin{array}{l}\tilde{n} \\
\tilde{n} \\
\tilde{n} \\
\stackrel{\gamma}{\sim}\end{array}$ & $\begin{array}{l}\hat{\sigma} \\
\text { م. } \\
\hat{\sigma} \\
\tilde{n}\end{array}$ & \\
\hline 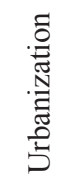 & 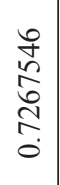 & $\begin{array}{l}n \\
\infty \\
n \\
\delta \\
o \\
\vdots \\
0\end{array}$ & $\mid \begin{array}{l}n \\
\infty \\
\infty \\
\infty \\
\infty \\
0 \\
0 \\
0\end{array}$ & 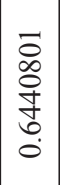 & $\mid \begin{array}{c}0 \\
\hat{2} \\
\stackrel{0}{2} \\
\stackrel{-}{-}\end{array}$ & $\mid \begin{array}{l}0 \\
\cdots \\
\alpha \\
\infty \\
\hat{\alpha} \\
\vdots \\
0\end{array}$ & 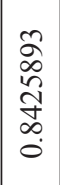 & $\begin{array}{l}\hat{\widehat{N}} \\
\infty \\
\hat{\sigma} \\
\hat{0}\end{array}$ & 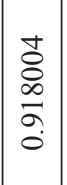 & 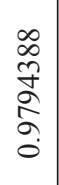 & $\begin{array}{l}\frac{a}{n} \\
\stackrel{n}{=}\end{array}$ & $\begin{array}{l}2 \\
\infty \\
\overrightarrow{0} \\
0 \\
0 \\
0\end{array}$ & $\begin{array}{l}n \\
\frac{n}{\alpha} \\
\hat{n} \\
\hat{\alpha} \\
\hat{o}\end{array}$ & \\
\hline
\end{tabular}

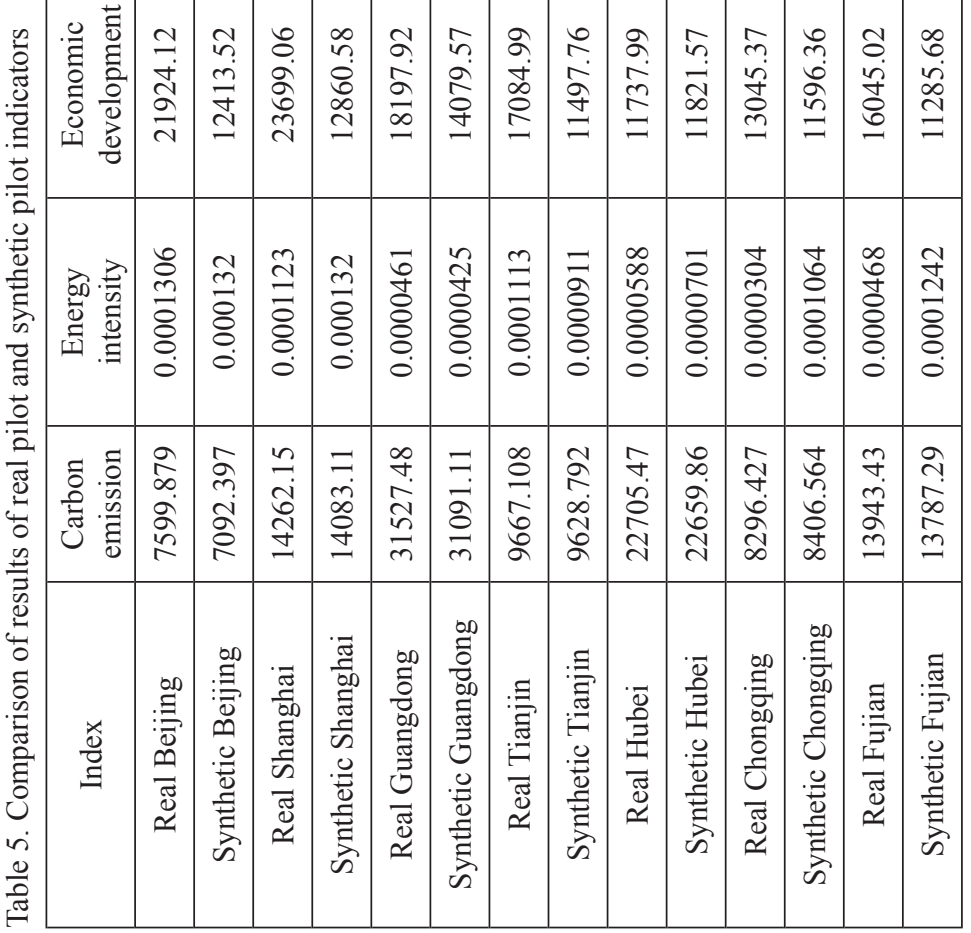




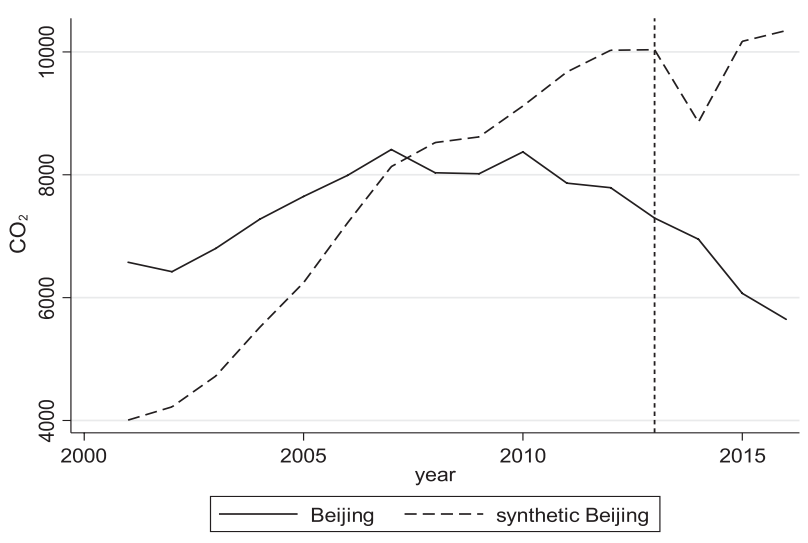

Fig. 3. Real Beijing and synthetic Beijing carbon emissions.

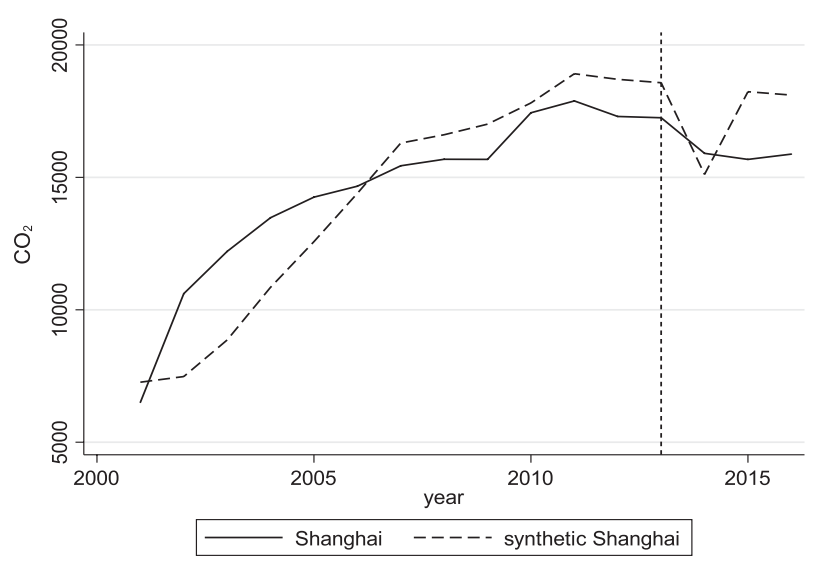

Fig. 4. Real Shanghai and synthetic Shanghai carbon emissions

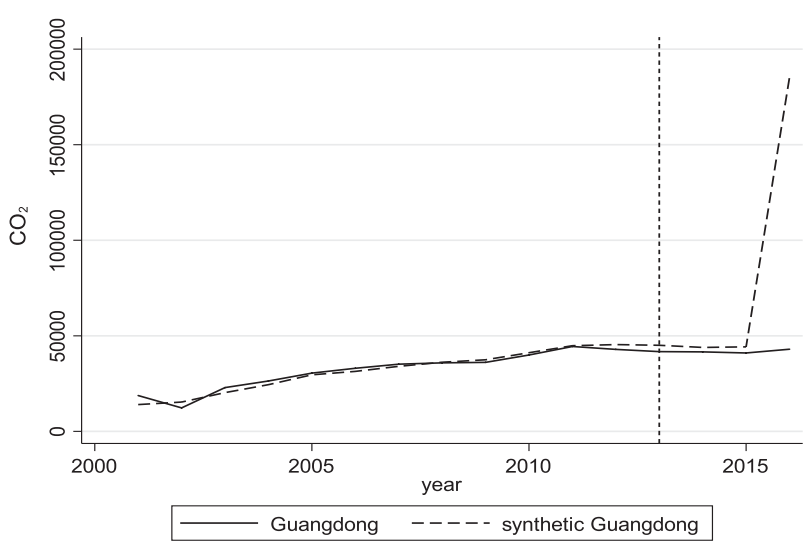

Fig. 5. Real Guangdong and synthetic Guangdong carbon emissions.

carbon trading are used as the control group areas. The control group is used to fit the anti-factual state of carbon trading in pilots, and then the carbon emissions in pilots are compared with those in real pilots so as to obtain the emission reduction effect in pilots. Shenzhen belongs to Guangdong Province, which cannot peel away from Guangdong, so consider them together. The key to SCM is to determine the specific weight of the

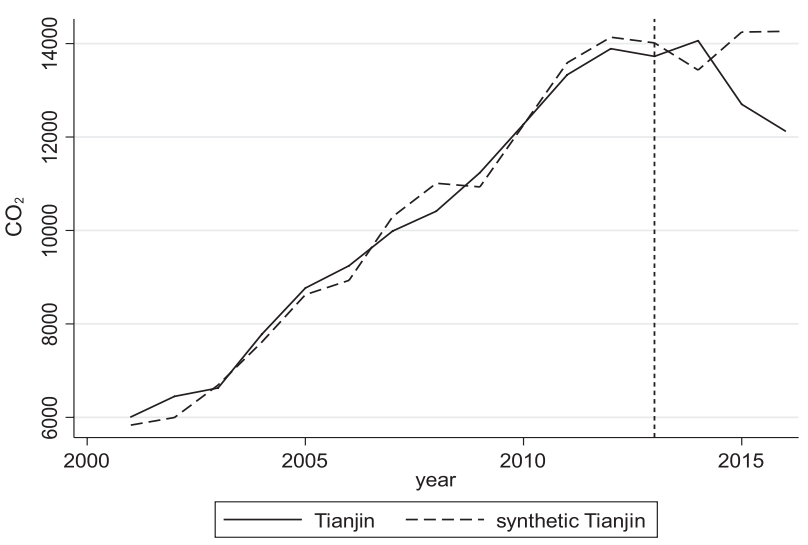

Fig. 6. Real Tianjin and synthetic Tianjin carbon emissions.

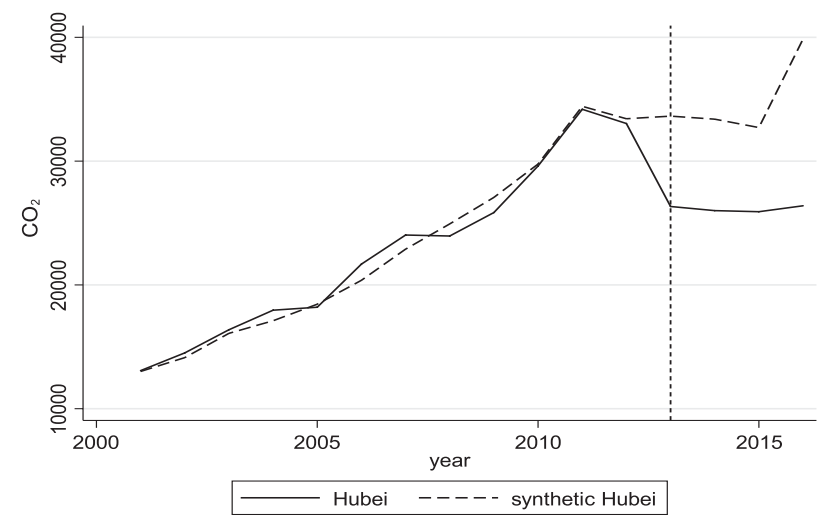

Fig. 7. Real Hubei and synthetic Hubei carbon emissions.

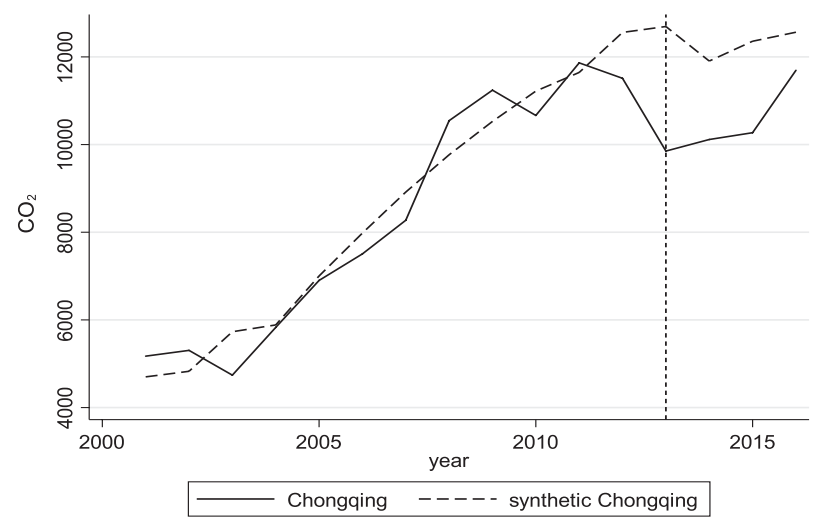

Fig. 8. Real Chongqing and synthetic Chongqing carbon emissions.

control group, and the results are shown in Table 4. The real and synthetic indicators in each pilot are shown in Table 5.

Using the carbon emission drivers decomposed by LMDI and the carbon emissions in 2001, 2005, 2009 and 2012 as explanatory variables of the synthetic control model, it draws the estimated results of the real pilots and the synthetic pilots. Table 5 shows the comparison between the real pilots and the synthetic pilots. 2013 as 


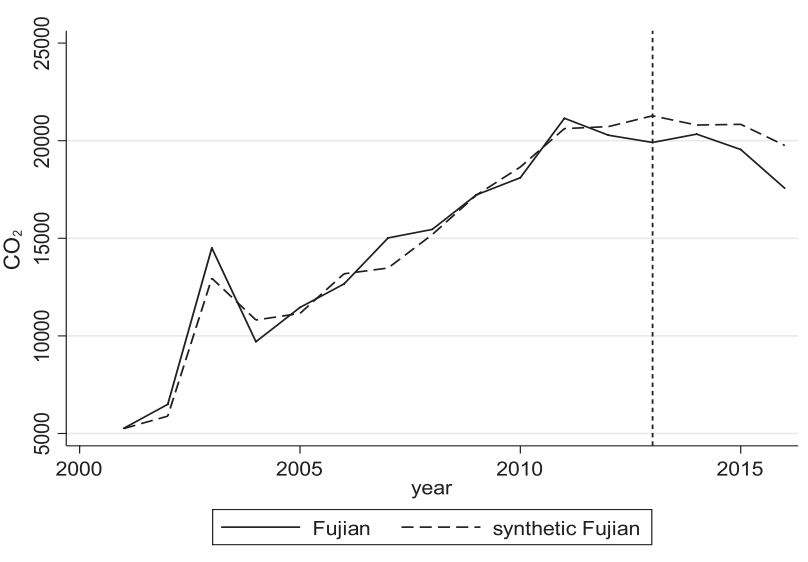

Fig. 9. Real Fujian and synthetic Fujian carbon emissions.

the policy implementation year, its real and synthetic indicators are better in fitting effect, which can be a better counter-factual state after the synthesis. The policy effect of each pilot can be intuitively expressed by Figs 3-9, which show 2013 as the policy implementation year, which better fits the synthetic pilots before the implementation of the overall effect of carbon emissions. It indicates that SCM can better replicate the growth path of carbon emissions in pilots. The amount of synthetic control after the implementation of the policy is higher than the real carbon emissions, and the difference is gradually becoming larger. The difference is the effect of emission reduction, and the pilots have an obvious emission reduction effect, which indicates that carbon emissions have been generally reduced after the implementing the carbon trading policy in Beijing, Tianjin, Guangdong, Hubei, Chongqing and Fujian.

\section{Placebo Test}

From the results in the previous section, we concluded that the policy effect of China's pilot carbon trading policy is significant. Fig. 10 takes Guangdong (Shenzhen) as an example to carry out the corresponding

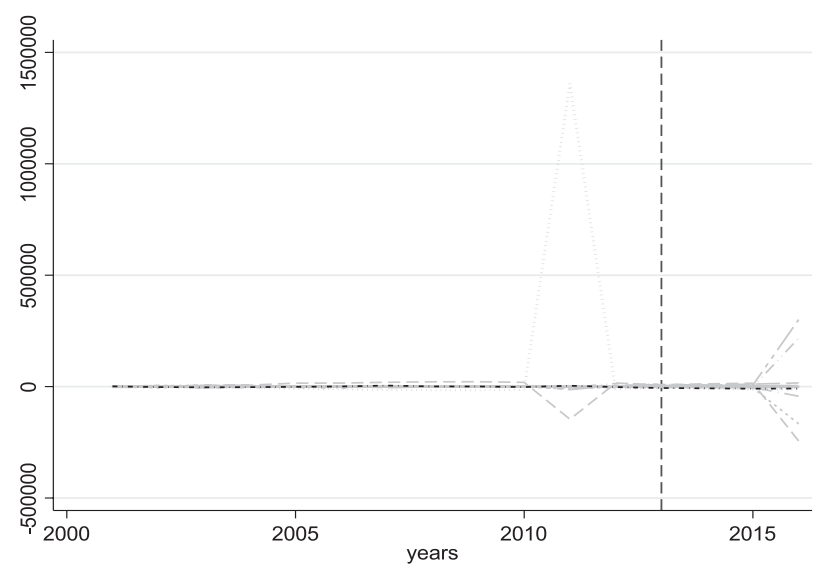

Fig. 10. Placebo test of carbon trading policy effect (taking Guangdong as an example). significance test, in which the black solid line is the policy effect of the pilot carbon market in Guangdong, and the other light-colored lines are the pseudo-policy effects obtained by the pseudo-intervention individuals in other 22 regions. If the original assumption that the carbon trading policy has no impact on the carbon emissions in pilots is valid, the estimated policy effect path should be more likely to appear. But in Fig. 10, the black solid line is in the more extreme part of all the path distributions, and only one region is under the black solid line. So in the absence of the original assumption, the probability of the real policy effect should be $1 / 23$, that is, $4.35 \%$, which is significant at the significance level of $5 \%$ and it can reject the original assumption that there is no policy effect. In this paper, the screening conditions selected in the placebo test are as follows. The mean square prediction error (MSPE) before intervention is less than twice as much as the MSPE in the treatment area. The placebo test results of carbon trading policy in Guangdong (Shenzhen) are shown in Fig. 10, and the placebo test results in other pilots are omitted here.

\section{Conclusions}

Conclusions can be drawn as follows. Firstly, carbon emissions in China show an increasing trend year by year, and there is obviously a state of high in the east and low in the west. As the largest carbon emitter in the world, energy consumption in China is still dominated by coal, which is bound to lead to an increase in carbon emissions year by year. China's development strategy is "to take the lead in developing the eastern region, to promote the large-scale development of the western region as a whole, to revitalize the northeast in an allaround way and to rise in the central region". Therefore, in the developed regions energy consumption is relatively large and its population density is high, which makes the carbon emissions in the eastern regions larger than those in the central or western regions. With the development of national strategy, inter-regional economic coordination and the promotion of low-carbon concepts, the growth rate of carbon emissions will slow down, while the difference of carbon emissions among regions will be gradually reduced. Secondly, the driving factors of carbon emissions in this paper are mainly energy structure, energy intensity, economic development, urbanization and population size. They have great contributions on carbon emissions. Driving economic development, promoting technical progress, reducing energy intensity, accelerating the process of urbanization and giving full play to the advantages of population size are very important for low-carbon development in regions. Thirdly, after China implementing the pilot carbon market policy, the carbon emissions in pilots generally show a downward trend, which indicates that the policy of carbon trading is effective. And it is of great significance for carbon 
abatement to establish and improve the perfect national unified carbon market in China. In order to perfect the national unified carbon market we can fully consider the regional characteristics and factors of carbon emissions to formulate regional carbon trading policy.

Recommendations are as follows. Firstly, it should speed up the coordinated development among regions, and consider the effective control while paying attention to economic development. It can give full play to the advantages of the regions, promote the emission reduction of backward areas from the advanced areas, form a benign situation of economic development and ecological security, and avoid the old road of "pollution first and then controlling". Secondly, the key to effective governance of carbon abatement is to clear the important drivers of carbon emissions in these regions. There are obvious individual characteristics in different parts of China, so the contributions of the factors to carbon emissions in different regions is different under the complete decomposition of LMDI. It is necessary for the local government to provide specific emission reduction rules on the basis of the overall reduction strategy of the central government so as to achieve the goal of global climate temperature control. Thirdly, in the process of popularizing the carbon market, it can improve carbon trading mechanisms according to the developing characteristics and emission reduction policies in each region. It is necessary to make full use of carbon trading to realize the effective control of emissions, which is a method for low transaction cost and high emission reduction efficiency.

\section{Acknowledgements}

This study is supported by a major project of the National Social Science Fund (N0. 15ZDC034), and the National Ministry of Education Humanities and Social Science Research Planning Fund Project of China (No. 18YJA790031) .

\section{Conflict of Interest}

The authors declare no conflict of interest.

\section{References}

1. STERNER T. The selection and design of policy instruments in environmental and natural resource management. Washington D.C.: RFF Press, 2002.

2. BAI Q., CHEN M. The distributionally robust newsvendor problem with dual sourcing under carbon tax and cap-andtrade regulations. Computers \& Industrial Engineering, 98, 260, 2016.

3. ZHANG Z., JIN X., YANG Q., ZHANG Y. An empirical study on the institutional factors of energy conservation and emissions reduction: Evidence from listed companies in China. Energy policy, 57, 36, 2013.
4. ZHANG Y.J., PENG Y.L., MA C.Q., SHEN B. Can environmental innovation facilitate carbon emissions reduction? Evidence from China. Energy Policy, 100, 18, 2017.

5. ALDY J.E., KRUPNICK A.J., NEWELL R.G., PARRY, I.W., PIZER W.A. Designing climate mitigation policy. Journal of Economic Literature, 48 (4), 903, 2010.

6. DODA B. How to price carbon in good times... and bad. Wiley Interdisciplinary Reviews: Climate Change, 7 (1), 135, 2016.

7. CROPPER M.L., OATES W.E. Environmental economics: a survey. Journal of economic literature, 30 (2), 675, 1992.

8. BAUMOL W.J., OATES W.E., BAWA W.S., BRADFORD D.F. The theory of environmental policy. Cambridge university press, 1988.

9. WEITZMAN M.L. Prices vs. quantities. The review of economic studies, 41 (4), 477, 1974.

10. KEOHANE N.O. Cap and trade, rehabilitated: Using tradable permits to control US greenhouse gases. Review of Environmental Economics and policy, 3 (1), 42, 2009.

11. BARRAGAN-BEAUD C., PIZARRO-ALONSO A., XYLIA M., SYRI S., SILVEIRA S. Carbon tax or emissions trading? An analysis of economic and political feasibility of policy mechanisms for greenhouse gas emissions reduction in the Mexican power sector. Energy policy, 122, 287, 2018.

12. TANG Y., LI S., XIA Q. Analysis on influence factors of domestic energy carbon emissions in China: based on STIRPAT model. Ecological Economy, 33 (5), 42, 2017.

13. CELLURA M., LONGO S., MISTRETTA M. Application of the structural decomposition analysis to assess the indirect energy consumption and air emission changes related to Italian households consumption. Renewable and Sustainable Energy Reviews, 16 (2), 1135, 2012.

14. LIN X., POLENSKE K.D. Input-output anatomy of China's energy use changes in the 1980s. Economic Systems Research, 7 (1), 67, 2005.

15. CHANG Y.F., LIN S.J. Structural decomposition of industrial $\mathrm{CO}_{2}$ emissions in Taiwan: an input-output approach. Energy Policy, 26 (1), 5, 1998.

16. MUKHOPAHYAY K., CHAKRABORTY D. India's energy consumption changes during 1973-1974 to 1991-1992. Economics Systems Research, 11 (4), 423, 2000.

17. DE NOOJJ M., VAN DER KRUK R., VAN SOEST D.P. International comparisons of domestic energy consumption. Energy Economics, 25 (4), 359, 2013.

18. ANG B.W. Decomposition analysis for policy making in energy: which is the preferred method. Energy Policy, 32 (9), 1131, 2014

19. ANG B.W., LIU N. Energy decomposition analysis: IDA model versus other methods. Energy Policy, 35 (3), 1426, 2007.

20. ANG B.W., CHEW E.P. Perfect decomposition techniques in energy and environmental analysis. Energy Policy, 31 (14), 1561, 2013

21. ELLERMAN A.D., DECAUX A. Analysis of post-Kyoto $\mathrm{CO}_{2}$ emissions trading using marginal abatement curves. MIT Joint Program on the Science and Policy of Global Change, Report NO.40, Cambridge, USA, 1998.

22. LOISEL R. Environmental climate instruments in Romania: A comparative approach using dynamic CGE modelling. Energy Policy, 37 (6), 2190, 2009.

23. HUBLER M., VOIGT S., LOSHEL A. Designing an emissions trading scheme for China - An up-to-date climate policy assessment. Energy Policy, 75, 57, 2014. 
24. LIN B., JIA Z. What will China's carbon emission trading market affect with only electricity sector involvement? A CGE based study. Energy Economics, 78, 301, 2019.

25. YIN J., YAN Q., LEI K., BALEZENTIS T., STREIMIKIENE D. Economic and Efficiency Analysis of China Electricity Market Reform Using Computable General Equilibrium Model. Sustainability, 11 (2), 350, 2019.

26. DONG F., DAI Y., ZHANG S., ZHANG X., LONG R. Can a carbon emission trading scheme generate the Porter effect? Evidence from pilot areas in China. Science of the Total Environment, 653, 565, 2019.

27. WANG H., CHEN Z., WU X., Nie X. Can a carbon trading system promote the transformation of a low-carbon economy under the framework of the porter hypothesis? Empirical analysis based on the PSM-DID method. Energy policy, 129, 930, 2019.

28. ZHOU B., ZHANG C., SONG H., WANG Q. How does emission trading reduce China's carbon intensity? An exploration using a decomposition and difference-indifferences approach. Science of the Total Environment, 676, 514, 2019.

29. YANG Z., FAN M., SHAO S., YANG L. Does carbon intensity constraint policy improve industrial green production performance in China? A quasi-DID analysis. Energy Economics, 68, 271, 2017.

30. WURLOD J.D., NOAILLY J. The impact of green innovation on energy intensity: An empirical analysis for 14 industrial sectors in OECD countries. Energy Economics, 71, 47, 2018.
31. SELDEN T.M., SONG D. Environmental quality and development: is there a Kuznets curve for air pollution emissions?. Journal of Environmental Economics and management, 27 (2), 147, 1994.

32. GILL A.R., VISWANATHAN K.K., HASSAN S. The Environmental Kuznets Curve (EKC) and the environmental problem of the day. Renewable and Sustainable Energy Reviews, 81, 1636, 2018.

33. WEN L., LIU Y. The peak value of carbon emissions in the Beijing-Tianjin-Hebei region based on the STIRPAT model and scenario design. Polish Journal of Environmental Studies, 25 (2), 823, 2016.

34. ELLIOTT R.J., SUN P., ZHU T. The direct and indirect effect of urbanization on energy intensity: A provincelevel study for China. Energy, 123, 677, 2017.

35. BRANNLUND R., GHALWASH T., NORDSTROM J. Increased Energy Efficiency and the Rebound Effect: Effects on consumption and emissions. Energy Policy, 29 (1), 1, 2007.

36. ABADIE A., GARDEAZABAL J. The economic costs of conflict: A case study of the Basque Country. American economic review, 93 (1), 113, 2003.

37. ABADIE A., DIAMOND A., HAINMUELLER J. Synthetic control methods for comparative case studies: Estimating the effect of California's tobacco control program. Journal of the American statistical Association, 105 (490), 493, 2010.

38. BAI J. Panel data models with interactive fixed effects. Econometrica, 77 (4), 1229, 2009. 